\title{
NEW CELLULOSE-BASED MATERIALS AS TRANSDERMAL TRANSFER SYSTEMS FOR BIOACTIVE SUBSTANCES
}

\author{
NARCIS ANGHEL, SORIN LAZĂR, BIANCA-IULIA CIUBOTARU, \\ LILIANA VEREŞTIUC* ${ }^{*}$ and IULIANA SPIRIDON \\ "Petru Poni” Institute of Macromolecular Chemistry, 41A, Gr. Ghica-Voda Alley, \\ 700487, Iasi, Romania \\ "Faculty of Medical Bioengineering, "Grigore T. Popa" University of Medicine and Pharmacy, \\ 9-13 Kogalniceanu Str., 700454, Iasi, Romania \\ ×Corresponding author: Narcis Anghel, anghel.narcis@icmpp.ro
}

Dedicated to the $70^{\text {th }}$ anniversary of the Department of Pulp and Paper, "Cristofor Simionescu" Faculty of Chemical Engineering and Environmental Protection,

"Gheorghe Asachi" Technical University of Iasi

The purpose of this study was to obtain and characterize some cellulose/collagen biocomposites comprising different antioxidant and anti-inflammatory substances. The structure of the obtained materials was investigated using scanning electron microscopy (SEM) and attenuated total reflection infrared spectroscopy (FTIR). Additionally, the mechanical and biological characteristics of the materials were evaluated in order to identify some potential applications. The properties of the studied materials suggest that they may potentially be applied as skin care products in the field of cosmetics.

Keywords: cellulose, collagen, hesperidin, quercetin

\section{INTRODUCTION}

The growing interest in biomaterials based on cellulose is due to numerous possibilities to enhance the functionalities and quality of the current generation of materials, as well as to their nontoxic character and low cost, as compared to other materials. The use of various natural substances, such as polysaccharides ${ }^{1,2}$ and proteins, with different medical applications, is well documented in the literature. Natural compounds, such as flavonoids, provide numerous opportunities for their exploitation, due to their antimicrobial, antibacterial and antiinflammatory activity, ${ }^{3,4}$ in the context in which consumers are more interested in their health nowadays.

Collagen is recognized for its biocompatibility and biodegradability, as well as for good permeability. Due to the repetitive array of receptor-recognition motifs present in its structure, collagen could improve the adhesion and differentiation of cells. ${ }^{5}$ The most abundant collagen in the human body, type I collagen has a fibrillar morphology. ${ }^{6}$ That is why, combining collagen and cellulose, it is possible to obtain materials with improved properties.

Cellulose is the most abundant polysaccharide in the world. It consists of linear glucose rings connected to each other through $\beta \quad(1 \rightarrow 4)$ glycosidic bonds. Some parameters, such as shape, size, and crystallinity, vary as a function of cellulose sources and the delignification process applied. Its amorphous region is easily accessible, while the crystalline region is harder to penetrate by various reactants. ${ }^{7}$ Nanoengineering of this polymer could allow the controlled delivery of various bioactive materials, including chemotherapeutic agents, anti-inflammatory drugs and antimicrobial compounds. ${ }^{8}$ There are some studies dedicated to the development of some biomaterials based on bacterial ${ }^{9,10}$ or cellulose derivatives ${ }^{11}$ and collagen. In this study, we have used microcrystalline cellulose as matrix.

Cellulose Chem. Technol., 53 (9-10), 879-884(2019) 
As we have mentioned above, the inclusion of natural compounds with antimicrobial and antiinflammatory activity could improve the final properties of the developed materials.

This study seeks to develop new cellulose/collagen formulations comprising different fillers and to investigate their mechanical and morphological properties. We have also characterized the bioadhesive properties of all the formulations in order to determine their potential for cosmetic or dermatological applications.

\section{EXPERIMENTAL}

Materials

Cellulose (CEL) from Sigma Aldrich ( 20 micrometers) was used as matrix. Collagen hydrolysate, a polypeptide made by further hydrolysis of denatured collagen, with a molecular weight of $96 \mathrm{kDa}$, hesperidin, quercetin, acetyl salicylic acid, and ascorbic acid were purchased from Sigma-Aldrich and used without further purification.

\section{Biocomposites manufacture}

The base matrix for these biocomposites was made by mixing cellulose with collagen. Each component had its role. Thus, cellulose functions as a reinforcing material that confers the mechanical strength of the support. Collagen was chosen to ensure bioadhesiveness. $^{12}$

The materials were obtained in the form of foil by the casting method, using the ratio of cellulose: collagen: bioactive principle of 4: 1: 0.05 . The base matrix components were solubilized in $\mathrm{DMAc} / \mathrm{LiCl}^{13}$ and then the bioactive compound was added at room temperature. The composites were dried in a vacuum oven at $40{ }^{\circ} \mathrm{C}$ in order to remove the solvent, washed with distilled water and then air dried at room temperature.

The bioactive materials were thus chosen to belong to the categories of anti-inflammatories (acetyl salicylic acid, e.g. aspirin) ${ }^{14}$ and antioxidants (ascorbic acid, hesperidin and quercetin). ${ }^{15-18}$

The samples were coded as follows: CEL cellulose; $\mathrm{CCO}-$ cellulose/collagen; $\mathrm{ASP}=\mathrm{CCO}+$ acetyl salicylic acid; ASC $=\mathrm{CCO}+$ ascorbic acid; HES $=\mathrm{CCO}+$ hesperidin and $\mathrm{QER}=\mathrm{CCO}+$ quercetin.

\section{Methods}

Attenuated total reflectance Fourier transform infrared spectroscopy (ATR) was used to evaluate the interactions between the materials components.

64 scans of all the samples were acquired using a Bruker Vertex 70 (Billerica, MA, USA) ATR-FTIR spectrometer, equipped with an ATR device ( $\mathrm{ZnSe}$ crystal), with a 45 angle of incidence. The scanning was recorded in the range from $4000 \mathrm{~cm}^{-1}$ to $600 \mathrm{~cm}^{-1}$ and a spectral resolution of $2 \mathrm{~cm}^{-1}$.

\section{Compression test}

The samples were placed between the compression plates of a computer-controlled Shimadzu testing machine, with a $500 \mathrm{~N}$ load cell. An initial compressive contact of $0.1 \mathrm{~N}$ was applied. The data were registered at a stroke of $1 \mathrm{~mm} / \mathrm{min}$. The test was performed at $22{ }^{\circ} \mathrm{C}$ and the compressive modulus was calculated from the slope of stress-strain curves between 0 and $10 \%$ strain.

\section{Scanning electron microscopy (SEM)}

The surface of all the specimens was analyzed by SEM (FEI QUANTA 200ESEM instrument), with an integrated EDX system, GENESIS XM2i EDAX with an SUTW detector. The samples were analyzed with a low-vacuum secondary electron detector at an accelerating voltage of $25.0 \mathrm{kV}$, at room temperature and 0.050 Torr internal pressure. The experiment was performed in triplicate and the magnification is indicated on the figure.

\section{Bioadhesivity test}

An TA.XTplus ${ }^{\circledR}$ analyzer from Stable Micro Systems was used to evaluate the adhesion force and work of adhesion. Before the tests, the samples were cut to a standard size to allow dropping on the support (a mobile cylinder component of the equipment). Bladder tissue and cellulose membrane with a surface of $4 \mathrm{~cm}^{2}$ were placed in the sample device. During the recordings, the cylindrical holder with the pieces of samples was lowered with $1 \mathrm{~mm} / \mathrm{s}$. The contact force and the contact time were established at $1 \mathrm{gF}$ and $30 \mathrm{~s}$, respectively. The test was performed several times for each sample.

\section{RESULTS AND DISCUSSION FTIR analysis}

The effects of different fillers within the cellulose/collagen hydrogels were investigated in terms of mechanical, morphological and biological properties.

FTIR measurements were performed in order to evaluate the crystallinity and hydrogen bond intensities for the obtained materials (Fig. 1). The total crystallinity index (TCI) was calculated as the ratio between the intensity of the band at 1376 $\mathrm{cm}^{-1}$ and that of the $-\mathrm{CH}_{2^{-}}$peak $\left(2902 \mathrm{~cm}^{-1}\right)$ chosen as reference, while the hydrogen bond intensity (HBI) - as the ratio between the absorbance at $3400 \mathrm{~cm}^{-1}$ and that at $1362 \mathrm{~cm}^{-1}$, according to Colom and Carrillo. ${ }^{19}$

As can be seen from Table 1, the presence of collagen in the polymeric matrix causes a decrease of the total crystallinity by about $40 \%$, compared to that of cellulose, together with a significant increase, on average of $80 \%$, of the intensity of hydrogen bonds, which is otherwise 
expected. As hesperidin and quercetin are amorphous substances, they decrease the total crystallinity, but establish new interactions through hydrogen bonds with the other components of the blends, which is reflected in the mechanical properties and bioadhesive characteristics of the new materials, as will be seen later.

The presented data show a close correlation between the chemical structure of the bioactive principles and the intensity of the hydrogen bonds, hesperidin being best retained by the polymeric material.

\section{Morphology analysis}

Further insights into the loaded cellulosecollagen materials were provided by SEM investigation.
The micrographs achieved with the scanning electron microscope (SEM) show that the obtained biomaterials have a relatively homogeneous structure (Fig. 2).

In the case of hesperidin (hesperitin-7rutinoside), a high degree of organization of the biomaterial can be observed (Fig. 2d), due to the interaction of the remaining rutinoside with the polymeric matrix. It appears that hesperidin forms clusters with parallel orientation, which are repeated at regular intervals. By comparison, the presence of salicylic acid and quercetin decreases the degree of structural organization and causes the appearance of pores with the corresponding consequence, i.e. the decrease of the intensity of the hydrogen bonds between the components of the biocomposite.

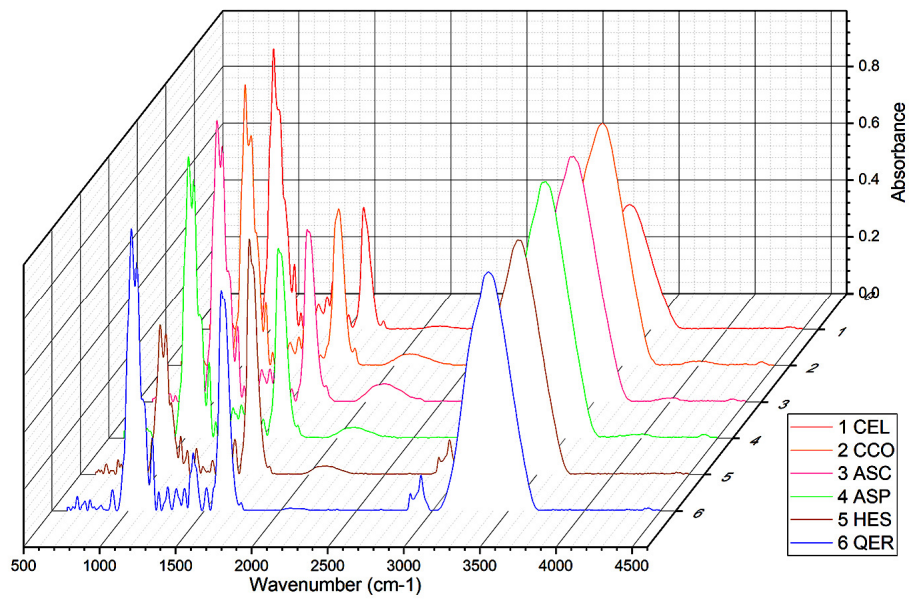

Figure 1: FTIR spectra of the studied biomaterials

Table 1

Total crystallinity index (TCI) and hydrogen bond intensity for the studied materials

\begin{tabular}{lcc}
\hline Sample & $\begin{array}{c}\text { Total crystallinity index (TCI) } \\
\text { A1376/A2902 }\end{array}$ & $\begin{array}{c}\text { Hydrogen bond intensity (HBI) } \\
\text { A3336/A1336 }\end{array}$ \\
\hline CEL & 0.841 & 5.069 \\
CCO & 0.495 & 10.713 \\
MAT & 0.500 & 8.367 \\
ASC & 0.665 & 7.664 \\
ASP & 0.928 & 10.671 \\
HES & 0.402 & 30.667 \\
QER & 0.624 & 10.948 \\
\hline
\end{tabular}




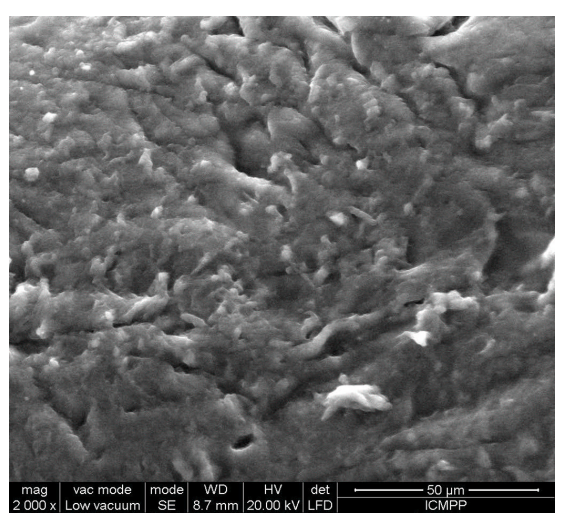

a)

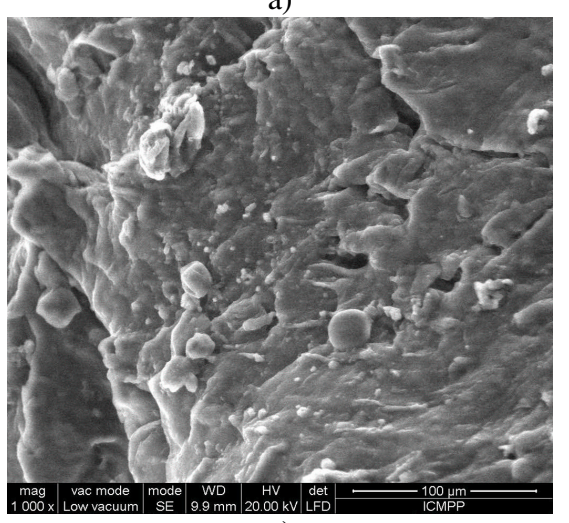

c)

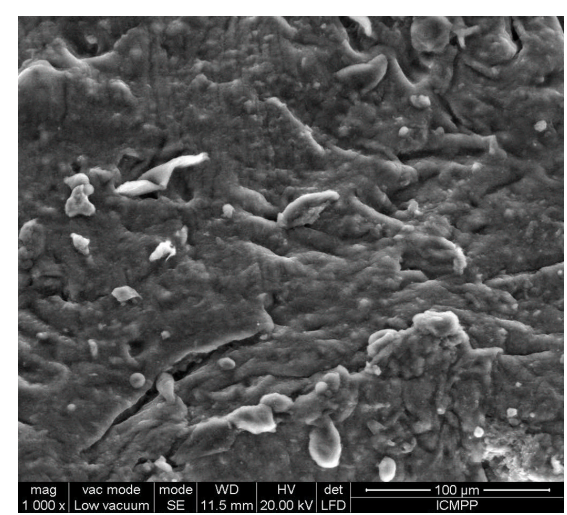

b)

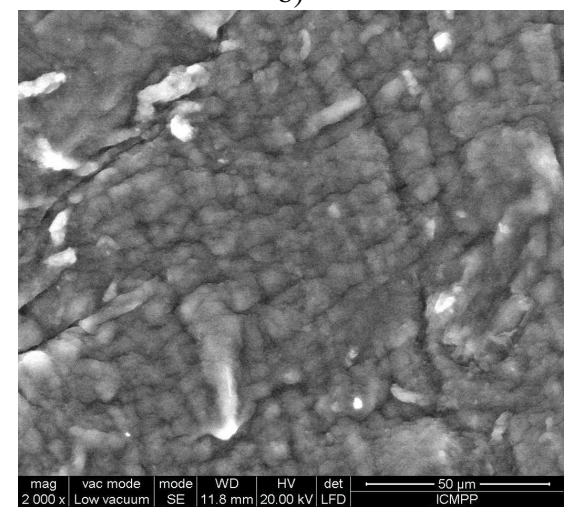

d)

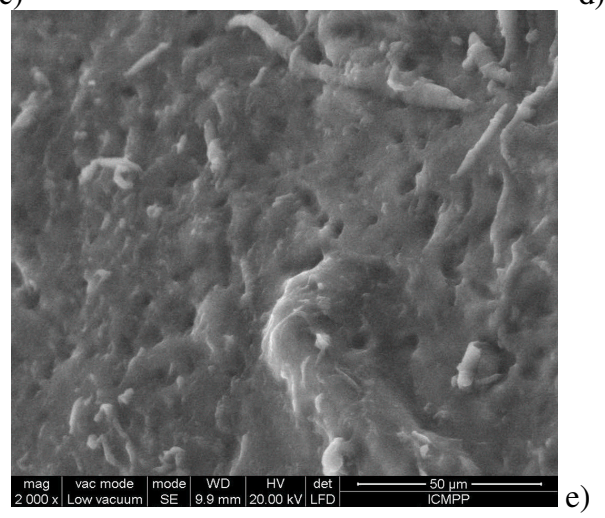

Figure 2: SEM micrographs for the tested materials; a) CCO; b) ASC; c) ASP; d) HES; e) QER

\section{Mechanical properties}

The results shown in Figure 3 indicate that the incorporation of different fillers into the cellulose/collagen polymer matrix resulted in a slow increase in compression strength, as compared to that of the matrix. The highest value of the compression modulus was observed for the cellulose $\left(\mathrm{E}_{\mathrm{c}}=2.79 \mathrm{kPa}\right)$, whereas the quercetinloaded material had the lowest stiffness
$\left(E_{c}=1.97 \mathrm{kPa}\right)$. An interesting behavior was remarked for the material comprising hesperidin. Its presence in the biocomposite caused a decrease in the elasticity of the material, which correlates very well with the value of the hydrogen bond intensity between the components (Table 1) and the degree of structural organization (Fig. 2d). 


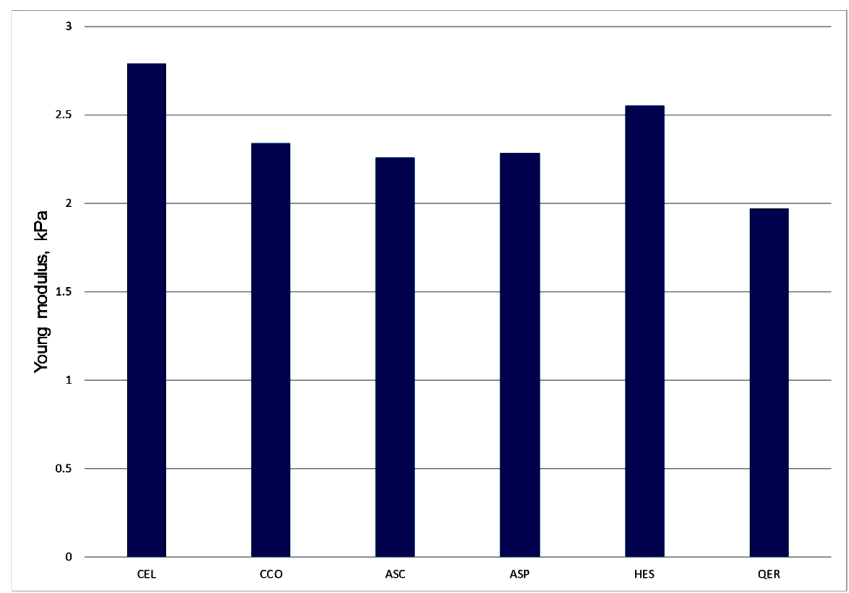

Figure 3: Mechanical properties of the composite biomaterials

Table 2

Adhesion force and work of adhesion for the obtained biomaterials

\begin{tabular}{lcc}
\hline Sample & Adhesion force, $(\mathrm{gF} \times 0.00980665), \mathrm{N}$ & Work of adhesion, $(\mathrm{N} \times \mathrm{s})$ \\
\hline CEL & 6.5 & 0.0059 \\
CCO & 15.0 & 0.0309 \\
ASC & 6.7 & 0.0066 \\
ASP & 5.9 & 0.0057 \\
HES & 8.5 & 0.0115 \\
QER & 5.2 & 0.0057 \\
\hline
\end{tabular}

\section{Bioadhesive properties}

The term bioadhesion is used to describe the attachment of a drug carrier system/formulation to an epithelial tissue due to the action of interfacial forces. ${ }^{20}$ The data (Table 2) suggest that the fillers interfere with the ability of the materials to adhere to the substrate. According to Table 2, the cellulose-collagen film presented the highest bioadhesive strength. The experimental data evidenced that the addition of collagen to the cellulosic matrix increased the bioadhesive force with $130.77 \%$. This adhesion improvement can be due to the increase of the hydrogen bond intensities between the materials and the membrane, as evidenced by the FTIR spectra (Table 1). The filler addition has induced a decrement of the bioadhesion force, which decreased for all the formulations (except that comprising hesperidin) to values similar or lower than that of cellulose. The greater force of bioadhesion and the mechanical adhesion work of the matrix containing hesperidin are due to the homogeneous structure, without pores, of the biomaterial.

According to the parameters calculated from the FTIR spectra, the TCI values are lower while the HBI values are higher, compared to those of the cellulose matrix. This means that more hydroxyl groups are available to interact by interand/or intramolecular hydrogen bonding. Thus, the presence of the filler encourages the formation of more hydrogen bonds and the polymer mobility is reduced. Rheological studies will clarify these aspects.

The work of adhesion values are in good agreement with the findings for the bioadhesive forces.

\section{CONCLUSION}

This paper describes the preparation and properties of novel cellulose collagen biomaterials comprising different bioactive compounds. It has been found that the incorporation of different fillers into the cellulose collagen polymer matrix resulted in a slow decrease in tensile strength, as compared to that of the matrix. The bioadhesive properties of all the formulations were evaluated as a function of their composition and it was found that the presence of hesperidin resulted in the best bioadhesion properties, while that of quercetin had the opposite effect. 
The final properties of the studied materials suggest that they may potentially be applied as skin care products in the field of cosmetics.

The present study is groundwork for future research, the structure-property relationships developed for these formulations will be further analyzed by rheological tests.

\section{REFERENCES}

1 S. Rençber, C. N. Cheaburu-Yilmaz, F. Aydin Köse, S. Yaprak Karavana and O. Yilmaz, Cellulose Chem. Technol., 53, $655 \quad$ (2019), https://doi.org/10.35812/CelluloseChemTechnol.2019. 53.64

2 M. D. Turliuc, A. I. Cucu, A. Cărăuleanu and C. F. Costea, Cellulose Chem. Technol., 52, 505 (2018), http://www.cellulosechemtechnol.ro/pdf/CCT78(2018)/p.505-513.pdf

3 I. Spiridon, Cellulose Chem. Technol., 52, 543 (2018),

http://www.cellulosechemtechnol.ro/pdf/CCT78(2018)/p.543-550.pdf

4 A. B. Ciubara, R. C. Tudor, L. Nechita, O. Tita, A. Ciubara et al., Rev. Chim., 69, 1247 (2018), http://www.revistadechimie.ro/article_eng.asp?ID=630 0

5 B. J. Huang, J. C. Hu and K. A. Athanasiou, Biomaterials, $\quad 98, \quad 1 \quad$ (2016), https://doi.org/10.1016/j.biomaterials.2016.04.018

6 M. Dobrota, S. Vlad, L. Gradinaru, M. Butnaru and G. Pircalabioru, Cellulose Chem. Technol., 53, 211 (2019),

https://doi.org/10.35812/CelluloseChemTechnol.2019. 53.21

7 R. J. Moon, A. Martini, J. Nairn, J. Simonsen and J. Youngblood, Chem. Soc. Rev., 40, 3941 (2011)

8 A. Sheikhi, J. Hayashi, J. Eichenbaum, M. Gutin, N. Kuntjoro et al., J. Control. Release, 294, 53 (2019), https://doi.org/10.1016/j.jconrel.2018.11.024
9 S. B. Lin, C. P. Hsu, L. C. Chen and H. H. Chen, Food Hydrocoll., 23, $2195 \quad$ (2009), https://doi.org/10.1016/j.foodhyd.2009.05.011

10 C. Wiegand, P. Elsner, U. C. Hipler and D. Klemm, Cellulose, $\quad 13, \quad 689$ https://doi.org/10.1007/s10570-006-9073-0

11 J. Kozlowska, N. Stachowiak and A. Sionkowska, Polym. Test., $\quad$ 69, $350 \quad$ (2018), https://doi.org/10.1016/j.polymertesting.2018.05.042

12 Y. Liu, S. C. Ng, J. Yu and W. B. Tsai, Colloid. Surfaces B: Biointerfaces, 174, 316 (2019), https://doi.org/10.1016/j.colsurfb.2018.10.077

13 S. Bano and Y. S. Negi, Carbohyd. Polym., 157, 1041

(2017)

https://doi.org/10.1016/j.carbpol.2016.10.069

14 A. V. Sorokin, Z. H. Yang, B. L. Vaisman, S. Thacker, Z. X. Yu et al., J. Nutr. Biochem., 35, 58 (2016), https://doi.org/10.1016/j.jnutbio.2016.05.012

15 E. A. González and M. A. Nazareno, LWT - Food Sci. Technol., 44, $558 \quad$ (2011), https://doi.org/10.1016/j.1wt.2010.09.017

16 O. Sagdic, I. Ozturk, G. Ozkan, H. Yetim, L. Ekici et al., Food Chem., 126, 1749 (2011), https://doi.org/10.1016/j.foodchem.2010.12.075

17 T. Barzegar, M. Fateh and F. Razavi, Sci. Hortic., 241, 293

(2018), https://doi.org/10.1016/j.scienta.2018.07.011

18 M. Sikora and M. Świeca, Food Chem., 239, 1160 (2018), https://doi.org/10.1016/j.scienta.2018.02.038

19 X. Colom and F. Carrillo, Eur. Polym. J., 38, 2225 (2002), https://doi.org/10.1016/S0014-3057(02)001325

20 R. Shaikh, T. R. Raj Singh, M. J. Garland, A. D. Woolfson and R. F. Donnelly, J. Pharm. Bioallied Sci., 3, 89 (2011), https://doi.org/10.2147/IJN.S75474 